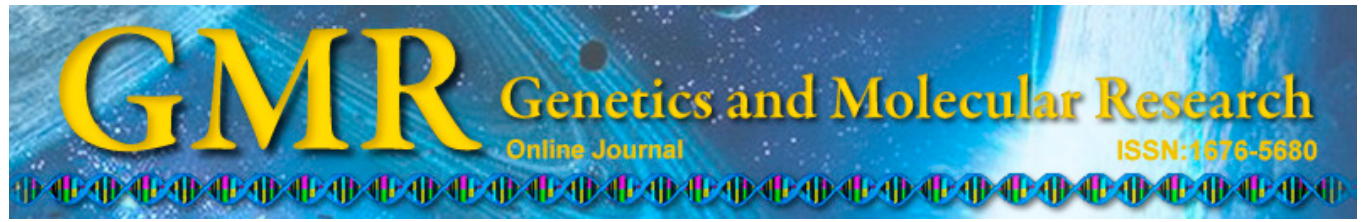

\title{
Diploid chromosome set of kissing bug Triatoma baratai (Hemiptera, Triatominae)
}

\author{
K.C.C. Alevi ${ }^{1}$, Y.V. Reis ${ }^{1}$, A.O. Borgueti ${ }^{1}$, V.J. Mendonça ${ }^{2}$, J.A. Rosa ${ }^{2}$ and \\ M.T.V. Azeredo-Oliveira ${ }^{1}$ \\ ${ }^{1}$ Laboratório de Biologia Celular, Departamento de Biologia, \\ Instituto de Biociências, Letras e Ciências Exatas, Universidade Estadual \\ Paulista "Júlio de Mesquita Filho", São José do Rio Preto, SP, Brasil \\ ${ }^{2}$ Laboratório de Parasitologia, Departamento de Ciências Biológicas, \\ Faculdade de Ciências Farmacêuticas, \\ Universidade Estadual Paulista "Júlio de Mesquita Filho", Araraquara, SP, Brasil \\ Corresponding author: K.C.C. Alevi \\ E-mail: kaiochaboli@hotmail.com
}

Genet. Mol. Res. 14 (1): 1106-1110 (2015)

Received May 22, 2014

Accepted October 28, 2014

Published February 6, 2015

DOI http://dx.doi.org/10.4238/2015.February.6.14

\begin{abstract}
Triatomines are insects that are taxonomically included in the Hemiptera order and Triatominae subfamily. Based on phenotypic similarity, capacity hybridization, and genetic and ecological aspects, the triatomine species can be grouped into specific complexes and subcomplexes. However, these groupings have not been confirmed. Cytogenetic analyses are important cytotaxonomic tools for improving the taxonomic knowledge of triatomines. Thus, we examined the karyotype of Triatoma baratai and compared the results with those of other species in the Matogrossensis subcomplex in order increase the understanding of vector potential. We also examined the cytotaxonomic classification of this insect. Triatoma baratai, similarly to other species that currently compose the Matogrossensis subcomplex, contains 22 chromosomes $(20 \mathrm{~A}+\mathrm{XY})$. Here, we describe the diploid chromosome set of $T$. baratai. We confirmed their current classification in the Matogrossensis subcomplex and demonstrated that the species in this
\end{abstract}


subcomplex present karyotype homogeneity.

Key words: Cytotaxonomy; Karyotype; Triatominae

\section{INTRODUCTION}

Triatomines are insects that are taxonomically included in the Hemiptera order and Heteroptera suborder within the Reduviidae family and Triatominae subfamily (Lent and Wygodzinsky, 1979). These organisms are medically important because all stages of the species that belong to the Triatominae subfamily are bloodsucking and susceptible to infection by the protozoan Trypanosoma cruzi Chagas, 1909 (Kinetoplastida, Trypanosomatidae) and are therefore potential vectors of Chagas disease (Noireau et al., 2009).

This illness is regarded as the second-most endemic disease in Latin America. In Brazil, approximately 2.5 million individuals are infected with T. cruzi (Neto and Pasternak, 2009). Because there is no specific treatment for Chagas disease, control of vector populations is considered as the main approach to minimizing the incidence of this disease (Hotez et al., 2012).

Deforestation and forest burning are important factors that influence the migration of vectors into urban regions. These organisms move to regions peridomiciliary and indoors in search of shelter and food, increasing the risk of disease infection (Dias and Schofield, 1998).

Based on phenotypic similarity, capacity hybridization, and genetic and ecological aspects, the triatomine species can be grouped into specific complexes and subcomplexes (Schofield and Galvão, 2009). However, new studies are still required to prove or disprove the groupings (Obara et al., 2012), because the correct classification of triatomines allows vector control programs focus on major vector species of Chagas disease (Alevi et al., 2012b).

Cytogenetic analyses are important cytotaxonomic tools (Ueshima et al., 1966; Pérez et al., 1992) that can be used to increase the phylogenetic understanding of triatomines. Using cytogenetic data, we excluded Triatoma melanocephala, T. tibiamaculata, and $T$. vitticeps, confirmed the inclusion of $T$. sherlocki and suggest the inclusion of T. lenti from the Brasiliensis subcomplex (Alevi et al., 2012a,b, 2013a,b,c,d,e, 2014a,b). Moreover, the taxonomic classification of other subcomplexes was also verified through cytogenetic analysis, such as for the Infestans subcomplex (T. infestans, T. platensis, and T. delpontei) and Sordida subcomplex (T. sordida, T. patagonica, and T. guasayana) (Panzera et al., 1995; 1997).

The Matogrossensis subcomplex is the new designation for the T. oliverai complex as proposed by Carcavallo et al. (2000). This subcomplex includes 9 species groups (Table 1) (Schofield and Galvão, 2009; Gardim et al., 2013; Gonçalves et al., 2013) from the Midwest region of Brazil (Obara et al., 2012).

The species T. baratai is present in the State of Mato Grosso do Sul (Gurgel-Gonçalves et al., 2012) and although considered wild they were found to inhabit homes (Obara et al., 2012).

Thus, the present study describes for the first time, the karyotype of T. baratai and compares with that of other species that make up the Matogrossensis subcomplex in order to enrich the knowledge about the biology of the vector potential and, mainly, auxiliary in the classification of this organism. 
Table 1. Species grouped in Martogrossensis subcomplex and their respective karyotypes.

\begin{tabular}{lll}
\hline Matogrossensis subcomplex & Karyotype & Described by: \\
\hline Triatoma baratai & $2 \mathrm{n}=22(20 \mathrm{~A}+\mathrm{XY})$ & This report \\
Triatoma costalimai & $2 \mathrm{n}=22(20 \mathrm{~A}+\mathrm{XY})$ & Dujardin et al. (2002) \\
Triatoma deaneorum & Not described & \\
Triatoma guazu & $2 \mathrm{n}=22(20 \mathrm{~A}+\mathrm{XY})$ & Dujardin et al. (2002) \\
Triatoma jatai & Not described & \\
Triatoma jurbergi & $2 \mathrm{n}=22(20 \mathrm{~A}+\mathrm{XY})$ & Dujardin et al. (2002) \\
Triatoma matogrossensis & $2 \mathrm{n}=22(20 \mathrm{~A}+\mathrm{XY})$ & Pérez et al. (1992) \\
Triatoma vandae & $2 \mathrm{n}=22(20 \mathrm{~A}+\mathrm{XY})$ & Panzera et al. (2010) \\
Triatoma williami & $2 \mathrm{n}=22(20 \mathrm{~A}+\mathrm{XY})$ & Dujardin et al. (2002) \\
\hline
\end{tabular}

\section{MATERIAL AND METHODS}

Two T. baratai males, assigned by the "Triatominae Insectarium" installed at the Departamento de Ciências Biológicas, Faculdade de Ciências Farmacêuticas, Araraquara campus, were included in this study. After removing and fixing seminiferous tubules of adult males on a cover slip, lacto-acetic-orcein was used for cytogenetic analysis (De Vaio et al., 1985), with modifications according to Alevi et al. (2012b). The biological material was analyzed using a Jenaval light microscope (Carl Zeiss AG, Jena, Germany) coupled to a digital camera and an image analyzer Axio Vision LE 4.8 (Carl Zeiss). The images were magnified by a factor of 100 .

\section{RESULTS}

Based on the analysis of metaphase I (Figure 1) and II, male T. baratai presented a set diploid chromosome $2 \mathrm{n}=22(20 \mathrm{~A}+\mathrm{XY})$. This chromosome number is common to all members of the Matogrossensis subcomplex (Table 1).

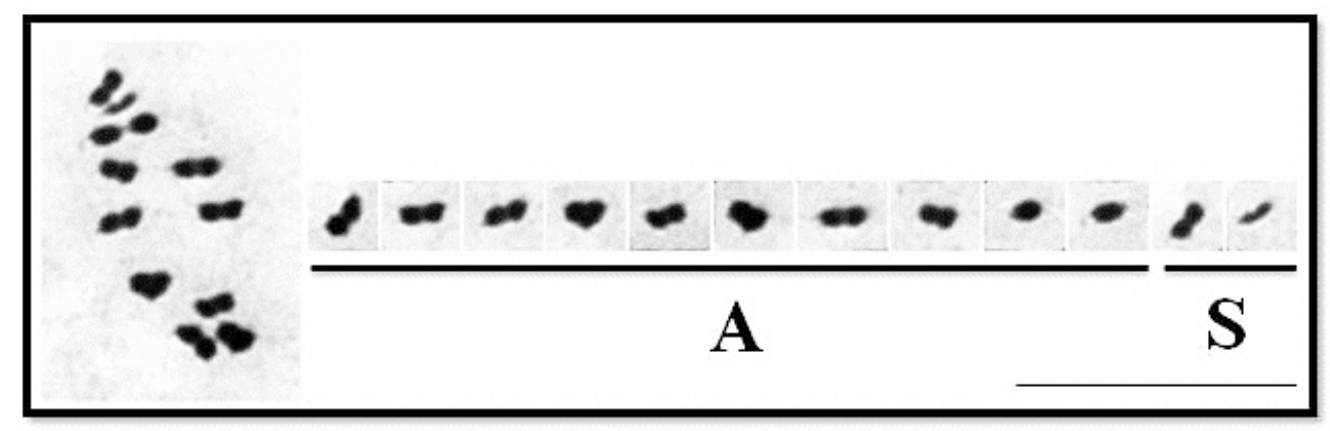

Figure 1. Karyotype of Triatoma baratai based on metaphase I with 22 chromosomes (20A + XY). A: autosomes. S: sex chromosomes. Bar: $10 \mu \mathrm{m}$.

\section{DISCUSSION}

Currently, 86 karyotypes of triatomines have been described in the literature (Alevi et al., 2013f). All species of the tribe Rhodiniini contain 22 chromosomes (20A + XY) (Panzera et al., 2010; Pita et al., 2013; Alevi et al., 2013f, 2015). The genus Panstrongylus show two karyotypic variations, P. megistus with $2 \mathrm{n}=18 \mathrm{~A}+\mathrm{X}_{1} \mathrm{X}_{2} \mathrm{Y}$ (Schreiber and Pellegrino, 1950) 
and $P$. lutzi with $2 \mathrm{n}=20 \mathrm{~A}+\mathrm{X}_{1} \mathrm{X}_{2} \mathrm{X}_{3} \mathrm{Y}$ (Santos, 2010). The genus Triatoma shows the most diverse karyotypes found in the Triatominae subfamily, including $2 \mathrm{n}=21,22,23,24$, and 25 chromosomes (Alevi et al., 2013f).

The number of chromosomes, although initially described as homogeneous in the Triatominae subfamily (Ueshima, 1966), is an important tool in systematic triatomines. Phylogeny can be examined from a karyosystematic perspective because although it is thought that the common ancestor possessed $2 \mathrm{n}=22$ chromosomes, numerical variations exist between organisms classified based on morphological and geographical traits as closely related species. This was observed in the Brasiliensis subcomplex (Schofield and Galvão, 2009; Alevi et al., 2012b).

Although species complexes are not formally recognized as taxonomic ranks and, thus, do not necessarily represent natural groups, they should be monophyletic (Justi et al., 2014). This underscores the importance of using different tools to assess the initial classification of these organisms. Triatoma baratai, similarly to all other species that currently compose the Matogrossensis subcomplex has 22 chromosomes (20 autosomes and 2 sex chromosomes) (Table 1). Therefore, in contrast to the Protracta, Lectularia, and Rubrofasciata complexes, the Matogrossensis subcomplex shows chromosomal homogeneity.

Thus, the diploid chromosome set of T. baratai, confirms their current classification in the Matogrossensis subcomplex and demonstrates that the species in the subcomplex show karyotype homogeneity.

\section{ACKNOWLEDGMENTS}

Research supported by Fundação de Amparo à Pesquisa do Estado de São Paulo (FAPESP) (Process 2013/19764-0), Conselho Nacional de Desenvolvimento Científico e Tecnológico (CNPq), and Fundação de Apoio à Pesquisa e Extensão de São José do Rio Preto (FAPERP).

\section{REFERENCES}

Alevi KCC, Mendonça PP, Pereira NP, Rosa JA, et al. (2012a). Karyotype and spermatogenesis in Triatoma lenti (Hemiptera: Triatominae), a potential Chagas vector. Gen. Mol. Res. 11: 4278-4284.

Alevi KCC, Mendonça PP, Suci M, Pereira NP, et al. (2012b). Karyotype of Triatoma melanocephala Neiva and Pinto (1923). Does this species fit in the Brasiliensis subcomplex? Infect. Gen. Evol. 12: 1652-1653.

Alevi KCC, Mendonça PP, Pereira NP, Guerra AL, et al. (2013a). Distribution of constitutive heterochromatin in two species of triatomines: Triatoma lenti Sherlock and Serafim (1967). and Triatoma sherlocki Papa, Jurberg, Carcavallo, Cerqueira \& Barata (2002). Infect. Gen. Evol. 13: 301-303.

Alevi KCC, Mendonça PP, Pereira NP, Rosa JA, et al. (2013b). Spermatogenesis in Triatoma melanocephala (Hemiptera: Triatominae). Gen. Mol. Res. 12: 4944-4947.

Alevi KCC, Mendonça PP, Pereira NP, Fernandes AL, et al. (2013c). Analysis of spermiogenesis like a tool in the study of the triatomines of the Brasiliensis subcomplex. C R Biolo. 336: 46-50.

Alevi KCC, Mendonça PP, Pereira NP, Rosa JA, et al. (2013d). Heteropyknotic filament in spermatids of Triatoma melanocephala and T. vitticeps (Hemiptera, Triatominae). Inv. Rep. Dev. 58: 9-12.

Alevi KCC, Mendonça PP, Pereira NP, Rosa JA, et al. (2013e). Análise das Regiões Organizadoras Nucleolares e da atividade nucleolar em Triatoma melanocephala e T. lenti, importantes vetores da doença de Chagas. Rev. Ciênc. Farm. Básica Apl. 34: 417-421.

Alevi KCC, Rosa JA and, Azeredo Oliveira MTV (2013f). Mini review: karyotypic survey in Triatominae subfamily (Hemiptera, Heteroptera). Entomol. Ornithol. Herpetol. 2: 106.

Alevi KCC, da Rosa JA and de Azeredo-Oliveira MT (2014a). Spermatogenesis in Triatoma melanica Neiva and Lent, 1941 (Hemiptera, Triatominae). J. Vector Ecol. 39: 231-233.

Alevi KCC, Rosa JA and Azeredo-Oliveira MT (2014b). Cytotaxonomy of the Brasiliensis subcomplex and the Triatoma 
brasiliensis complex (Hemiptera: Reduviidae: Triatominae). Zootaxa 3838: 583-589.

Alevi KCC, Ravazi A, Mendonça VJ, and Rosa JA (2014c). Karyotype of Rhodnius montenegrensis (Hemiptera, Triatominae). Gen. Mol. Res. in press.

Alevi KCC, Ravazi A, Mendonça VJ, Rosa JA, et al. (2015). Karyotype of Rhodnius montenegrensis (Hemiptera, Triatominae). Gen. Mol. Res 14: 222-226.

Carcavallo RU, Jurberg J, Lent H, Noireau F, et al. (2000). Phylogeny of the Triatominae (Hemiptera: Reduviidae). Proposals for taxonomic arrangements. Entomol. Vect. 7: 1-99.

De Vaio ES, Grucci B, Castagnino AM, Franca ME, et al. (1985). Meiotic differences between three triatomine species (Hemiptera: Reduviidae). Genetica 67: 185-191.

Dias JCP and Schofield CJ (1998). Controle da transmissão transfusional da doença de Chagas na Iniciativa do Cone Sul. Rev. Soc. Bras. Med. Trop. 3: 373-383.

Dujardin JP, Schofield CJ and Panzera F (2002). Los vectores de la enfermedad de Chagas. Académie Royale des Sciences d'Outre-Mer, Brussels, Belgium.

Gardim S, Rocha CS, Almeida CE, Takiya DM, et al. (2013). Evolutionary relationships of the Triatoma matogrossensis subcomplex, the endemic triatoma in Central-Western Brazil, based on mitochondrial DNA sequences. Am. J. Trop. Med. Hyg. 2013: 766-774.

Gonçalves TCM, Teves-Neves SC, Santos-Mallet, Carbajal-de-la-Fuente, et al. (2013). Triatoma jatai sp. Nov. in the state of Tocantins, Brazil (Hemiptera: Reduviidae: Triatominae). Mem. Inst. Oswaldo Cruz. 108: 429-437.

Gurgel-Gonçalves R, Galvão C, Costa J and Peterson AT (2012). Geographic distribution of Chagas disease vectors in Brazil based on ecological niche modeling. J. Trop. Med. 2012: 15.

Hotez PJ, Dumonteil E, Woc-Colburn L, Serpa JA, et al. (2012). Chagas Disease: "The New HIV/AIDS of the Americas." PLoS Negl. Trop. Dis. 6: e1498.

Justi SA, Russo CAM, Mallet JRS, Obara MT, et al. (2014). Molecular phylogeny of Triatomini (Hemiptera: Reduviidae: Triatominae). Paras. Vect. 7: 149.

Lent H and Wygodzinsky P (1979). Revision of the Triatominae (Hemiptera: Reduviidae) and their significance as vector of Chagas's disease. Bul. Am. Mus. Nat. Hist. 163: 123-520.

Neto VA and Pasternak J (2009). Centenário da doença de Chagas. Rev. Saúde Publica 43: 381-382.

Noireau F, Diosque P and Jansen AM (2009). Trypanosoma cruzi: adaptation to its vectors and its hosts. Vet. Res. 40: 26.

Obara MT, Barata JMS, Rosa JA, Ceretti-Junior W, et al. (2012). Description of the female and new records of Triatoma baratai Carcavallo \& Jurberg, 2000 (Hemiptera: Heteroptera: Reduviidae: Triatominae) from Mato Grosso do Sul, Brazil, with a key to the species of the Triatoma matogrossensis subcomplex. Zootaxa 3151: 63-68.

Panzera F, Pérez R, Panzera Y, Alvarez F, et al. (1995). Karyotype evolution in holocentric chromosomes of three related species of triatomines (Hemiptera-Reduviidae). Chromosome Res. 3: 143-150.

Panzera F, Hornos S, Pereira J, Cestau R, et al. (1997). Genetic variability and geographic differentiation among three species of triatomine bugs (Hemiptera-Reduviidae). Am. J. Trop. Med. Hyg. 57: 732-739.

Panzera F, Perez R, Panzera Y, Ferrandis I, et al. (2010). Cytogenetics and genome evolution in the subfamily Triatominae (Hemiptera, Reduviidae) Cytogen. Genome Res. 128: 77-87.

Pérez R, Panzera Y, Scafiezzo S, Mazzella MC, et al. (1992). Cytogenetics as a tool for Triatominae species distinction (Hemiptera- Reduviidade). Mem. Inst. Oswaldo Cruz 87: 353-361.

Pita S, Panzera F, Ferrandis I, Galvão C, et al. (2013). Chromosomal divergence and evolutionary inferences in Rhodniini based on the chromosomal location of ribosomal genes. Mem. Inst. Oswaldo Cruz 108: 376-382.

Santos SM (2010). Estudo citogenético de quatro espécies de triatomíneos (Hemiptera: Reduviidae). Doctoral thesis, Universidade Federal de Viçosa, Minas Gerais, Brasil.

Schofield CJ and Galvão C (2009). Classification, evolution, and species groups within the Triatominae. Acta Trop. 110: $88-100$.

Schreiber G and Pellegrino J (1950). Eteropicnosi di autosomi come possibile meccanismo di speciazione. Sci. Genet. 3 : 215-226.

Ueshima N (1966). Cytotaxonomy of the triatominae (Reduviidae: Hemiptera). Chromosoma 18: 97-122. 